\title{
The Zombie Apocalypse and COVID-19
}

\author{
Laura Hirshbein ${ }^{1}$ (D)
}

Received: 25 March 2020 / Accepted: 7 June 2020 / Published online: 17 June 2020

(C) Academic Psychiatry 2020

In February of 2020, a resident and I took care of a young woman on the adult psychiatric inpatient unit of our midwestern, academic hospital. The patient had been admitted due to suicidal thoughts. Her usual coping mechanisms for handling her distress - compulsive hand washing, disordered eating, substance use (mostly marijuana vaping), and superficial self-injurious behaviors-were no longer working for her. She was having fantasies of ending her life by jumping off a parking garage. Why was she so distressed? She was consumed by fears. She worried that her mother was going to get cancer and die. She worried that every severe thunderstorm would turn into a hurricane. And she admitted that her greatest fear was of the zombie apocalypse.

This was a great case to teach cognitive behavior therapy and exposure techniques. The resident consulted our anxiety disorder experts and got handouts for the patient. He helped her rank the intensity of her worries from minor (being given a plate instead of her usual bowl when her mother made dinner) to more severe (massive thunderstorms) to the most catastrophic - the zombie apocalypse. The patient responded quite well to reassurance and to exposure hierarchies. She was able to giggle when it was pointed out that our state was geographically isolated from hurricanes. She acknowledged that lying awake at night or refusing to leave her house for work because of fears of the zombie apocalypse was so irrational as to be comical. We were able to discharge this young woman after a few days, and she successfully transitioned her to a partial hospital program where she continued to work on exposure exercises.

I have been thinking about this woman and her fears, though, as our worlds have shut down in the past couple of weeks due to the COVID-19 pandemic. Right now, it really does feel like the zombie apocalypse. We have been told that it

Laura Hirshbein

lauradh@umich.edu

1 University of Michigan, Ann Arbor, MI, USA is highly risky to even venture out of the house. Going to work is only possible for those of us whose occupations involve essential activities - including health care and some service industries. People are frightened, and no one knows whether other people they encounter on the street or in a store have been infected. We are warned that if we are not careful with our interactions, we could all die. Public commentators have pointed out that it is challenging for individuals with obsessive-compulsive disorder (OCD) and other obsessive fears to manage information coming out of public health departments. Instead of learning how to decrease obsession with cleanliness and contamination, individuals with OCD are hearing that they should be more concerned. As I reflect on my former patient, I hope that she is doing okay and is able to handle all of this without a relapse to suicidal thoughts (though the partial program she was enrolled in closed because of realistic fears about contamination and exposure to germs).

As New York Times columnist Frank Bruni pointed out, the COVID-19 pandemic is harder for us as a society than other disasters because we are robbed of our ability to gather together for human comfort [1]. These circumstances also highlight how much our assumptions about psychiatric treatment are dependent on historical time and place. Sigmund Freud's theories of teeming conflicts within the inner recesses of the unconscious reflected his context of trying to work within a world of lurking antisemitism in late nineteenth- and early twentieth-century Austria [2]. In the 1950s, at a time of enormous cultural fear about the potential for nuclear warfare, anxiolytics became best-sellers within the USA [3]. I would argue that cognitive behavior therapy - the idea of talking back to irrational thoughts and fears - was only possible in a post-war context of relative affluence. Aaron Beck did important work in creating structures to help patients to be realistic in their engagement with the world [4]. At the same time, though, his identification of cognitive distortions only works in a context of shared reality that catastrophic thinking is wrong. We are not in that context now!

If the resident and I had to take care of this patient today, we would probably reach for dialectical behavior therapy. The 
work of Marsha Linehan [5] and others to address the reality of trauma-based fears might do the most for us as we try to manage our patients in this context. We can practice being mindful of where we are with patients, that we are only going to concentrate on the moments in front of us instead of being consumed by the enormity of the world crisis. We can work on learning how to regulate our hopes, fears, and grief about everything that we are losing as a society. We can improve our ability to clearly and effectively communicate with each other, especially when we have to ask for help. And we can learn to ride the waves of our distress as we accept that we are doing the best that we can, but we can always strive to do better.

\section{Compliance with Ethical Standards}

Disclosure The author has no conflicts of interest.

\section{References}

1. Bruni F. Why the Coronavirus is so much worse than Sept. 11. New York: New York Times; 2020.

2. Gilman SL. Freud, race, and gender. Princeton University Press: Princeton; 1993.

3. Tone A. The age of anxiety: a history of America's turbulent affair with tranquilizers. New York: Basic Books; 2008.

4. Beck AT. Cognitive therapy and the emotional disorders. New York: International Universities Press; 1976.

5. Linehan MM. DBT skills training manual. New York: Guilford Press; 2014.

Publisher's Note Springer Nature remains neutral with regard to jurisdictional claims in published maps and institutional affiliations. 